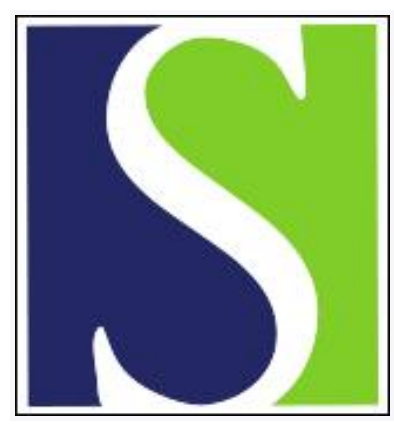

Scand J Work Environ Health 1985;11(6):495-497

https://doi.org/10.5271/sjweh.2196

Issue date: Dec 1985

State-dependent learning during chronic trichloroethylene exposure.

by Gade A, Jensen HH

Refers to the following text of the Journal: 1980;6(1):40-47

This article in PubMed: www.ncbi.nlm.nih.gov/pubmed/4095528

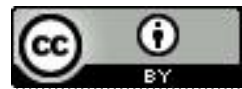


Scand J Work Environ Health 11 (1985) 495-497

\section{State-dependent learning during chronic trichloroethylene exposure}

Behavioral tests of solvent-exposed animals are being used increasingly to elucidate not only narcotic effects at various concentrations of organic solvents, but also putative irreversible effects on the central nervous system after long-term exposure. We wish to draw attention to a behavioral phenomenon, ie, state-dependent learning, the operation of which may erroneously be interpreted as behavioral impairment indicative of brain lesions. As an illustration of the phenomenon and how readily it can be misinterpreted, we have chosen an experiment by Kjellstrand et al ("Irreversible Effects of Trichloroethylene Exposure on the Central Nervous System'') that was published in 1980 by the Scandinavian Journal of Work, Environment \& Health (8).

Kjellstrand et al (8) exposed mongolian gerbils to $320 \mathrm{ppm}\left(1.72 \mathrm{~g} / \mathrm{m}^{3}\right)$ of trichloroethylene continuously for nine months. During this period the spatial memory of the animals was trained and tested in a maze. No significant differences in the number of correct choices were found between the trichloroethylene group and an air-exposed control group. Eleven days after the end of the trichloroethylene exposure, the animals were tested again. Every second day during this test, they were exposed to $2300 \mathrm{ppm}\left(12.6 \mathrm{~g} / \mathrm{m}^{3}\right)$ of 1,1,1-trichloroethane for $6 \mathrm{~h}$. Again no statistically significant differences between the trichloroethylene-exposed group and the control group were found, either on 1,1,1-trichloroethane days or on days free of $1,1,1$ -trichloroetnane. It was, however, found that on days when exposed to 1,1,1-trichloroethane, the animals previously exposed to TCE made more correct choices in the maze than on days when not exposed, whereas the control group made fewer. This test was repeated $75 \mathrm{~d}$ after the end of trichloroethylene exposure with attenuated but essentially similar results as $11 \mathrm{~d}$ after the trichloroethylene exposure.

The results were interpreted as showing that irreversible effects on the central nervous system were caused by exposure to $320 \mathrm{ppm}$ of trichloroethylene during nine months. It was noted that the effects could not be directly observed as changes in the behavior of the animals but could be revealed in almost every single animal by treatment with 1,1,1-trichloroethane. The authors speculated that covert toxicologic damage might exist in humans exposed to volatile solvents and that the effects may be unmasked by alcohol, stress, or age. The authors failed to discuss why the trichloroethylene-exposed group made more correct choices during the presumed unmasking condition (1,1,1-trichloroethane exposure) than on the exposure- free days. This very fact, however, is logically damaging for the validity of their interpretation. In later publications the results have been referred to.in terms of tolerance indicating some kind of neurochemical adaptation $(9,10)$.

\section{State-dependent learning}

The seemingly enigmatic data of Kjellstrand et al (8) conform closely to what would be predicted from a theory of state-dependent learning (13). Recall of events or behavior learned under the influence of a drug is facilitated by a similar drug state during the test of retention. Likewise, reproduction from learning during a no-drug state is impaired under subsequent drug influence when compared to the no-drug state. The phenomenon is known in man during the influence of alcohol and was clearly described as self-observation by the Danish author Aksel Sandemose (14):

When I had drunk one third of the bottle I corked
the bottle to bury it for some later time. Then I re-
membered that such a bottle was hidden not far from
where I was sitting - it came to my mind at just the
same state of drunkenness as when I was burying
it. . . Certain things appear in memory only when
you are in the same state as when that thing happened.
In fever I have suddenly remembered old hallucina-
tions [p 101].

The dissociation which occurs between the drug and the no-drug state may be symmetrical, ie, the learned response is not transferred between drug/no-drug states or between no-drug/drug states, but only between drug/drug, and no-drug/no-drug states. When the response fails to transfer only between drug and no-drug states, the dissociation is said to be asymmetrical (12).

State-dependent learning has been experimentally demonstrated with the use of a large number of drugs acting upon the central nervous system $(5,12)$. The basis of state-dependent learning is not known, but it may be assumed that a drug having this effect upon learning acts in the stimulus complex as a discriminative stimulus, or it affects the formation of memory traces in a drug-specific manner. In either case the reproduction of the learned material is facilitated when the retrieval of memory traces is again activated by the drug. The latter assumption could explain why certain drugs produce asymmetrical dissociation, as responses learned in the no-drug state have not been coded drug specifically (12). 
Ethanol, anesthetic agents, and organic solvents are believed to exert fluidizing effects on cell membranes, and the development of functional tolerance may involve compensatory changes in membrane fatty-acid composition $(10,11)$. Whether these and the possible secondary changes in synapses and neurotransmitter function are involved in state-dependent learning is unknown and merits consideration.

The present data (8) indicate that trichloroethylene and 1,1,1-trichloroethane, both of which are chlorinated hydrocarbons, are capable of producing statedependent learning. The effect may be seen as rather weak, but significant, and very consistent and reproducible. The dissociation tends to be symmetrical, although statistical significance between groups was not obtained in this respect. Animals trained, however, during trichloroethylene administration and subsequently tested during air exposure (drug/no drug) showed amnesia in comparison to responding on days when exposed to 1,1,1-trichloroethane (drug/drug). The average number of correct choices in the maze was 13.0 and 13.6, respectively, values statistically significant at the 0.05 level of confidence. Animals air-exposed during learning had a mean of 12.9 correct responses in the no drug/drug condition, and 13.7 in the no drug/no drug condition. This response pattern is what would be expected in a conventional experiment designed to demonstrate state-dependent learning, eg, symmetrical dissociation. Whether the effect with identical solvents during both learning and reproduction would have been greater than that seen with two closely related solvents remains conjectural. Obviously full acceptance of our interpretation, and generalization to other solvents, should await replications.

We are not aware of previous demonstrations of state-dependent learning during solvent exposure. This circumstance does not preclude its common occurrence, however, or its possible confounding effect in other studies, as its demonstration requires the testing of retention under both exposure and no-exposure conditions. In experimental studies of the chronic effects of long-term exposure, testing is required during exposure-free periods in order to separate the acute from the chronic effects. We suggest that the additional control of testing during exposure should also be included in such designs to test for state-dependent learning effects or that such studies avoid the testing of behavior learned or tested during the period of exposure.

The concept of state-dependent learning may also be relevant to symptoms in solvent-exposed humans. Memory trouble has been recorded as a prominent complaint of exposed workers $(1,6)$, but generally it has not been substantiated in controlled cross-sectional (4) or clinical studies $(2,3)$ with tests of learning and memory. A possible explanation of this discrepancy (albeit only one of several possible explanations) may be that the exposed person may experience true lapses of memory due to daily shifts between exposure and no-exposure states, whereas studies of memory have usually involved the same state, during which memory may be normal. This hypothesis could be tested in human chamber exposure experiments with slight modifications of the common experimental designs to allow for tests of transfer between the four combinations of exposure and no-exposure states.

The continuing search for possible long-term neural and behavioral effects of organic solvents is laudable. In this kind of research it should be remembered, however, that behavior is complex, and the relationships between chemical exposure and behavior may be neither simple nor easily described solely in terms of traditional brain-behavior concepts. State-dependent learning during solvent exposure, in itself a phenomenon with methodological and possibly clinical implications $(5,7)$, is an example of how behavioral alterations may mistakenly be taken to imply irreversible brain damage.

\section{References}

1. Arlien-Søborg P, Bruhn P, Gyldensted C, Melgaard B. Chronic painters' syndrome. Acta Neurol Scand 60 (1979) $149-156$

2. Gade A, Mortensen EL, Udesen H. The pattern of intellectual impairment in toxic encephalopathy. Presented at the International Conference on Organic Solvent Toxicity, Stockholm 15-17 October 1984.

3. Gade A, Mortensen EL, Udesen H, Bruhn P. On the importance of control data and background variables in the evaluation of neuropsychological aspects of brain functioning. In: World Health Organization. Proceedings of the Second International Symposium on Neurobehavioural Methods, Copenhagen Aug 6-9, 1985. Copenhagen 1985, pp 91-96. (WHO environmental health series, document 3).

4. Gamberale F. Use of behavioral performance tests in the assessment of solvent toxicity. Scand J Work Environ Health 11 (1985): suppl 1, 65-74.

5. Ho BT, Richards DW, Chute DL, ed. Drug discrimination and state dependent learning. Academic Press, New York, NY 1978.

6. Husman K. Symptoms of car painters with long-term exposure to a mixture of organic solvents. Scand J Work Environ Health 6 (1980) 19-32.

7. Jensen $\mathrm{HH}$, Hutchings B. Conditioned emotional responses with diazepam in normal subjects: A psychophysiological study of state dependent learning. Presented at the British Psychological Society's annual conference, Warwick, April 1984.

8. Kjellstrand P, Lanke J, Bjerkemo M, Zetterqvist L, Månsson L. Irreversible effects of trichloroethylene exposure on the central nervous system. Scand J Work Environ Health $6(1980)$ 40-47.

9. Kyrklund T, Alling C, Haglid K, Kjellstrand P. Chronic exposure to trichloroethylene: Lipid and acyl group composition in gerbil cerebral cortex and hippocampus. Neuro Toxicol 4 (1983) 35-42.

10. Kyrklund T, Goracci G, Haglid KG, Rosengren L, Porcellati G, Kjellstrand P. Chronic effects of trichloroethylene upon S-100 protein content and lipid composition in gerbil cerebellum. Scand J Work Environ Health 10 (1984) 80-93.

11. Melgaard B. The neurotoxicity of ethanol. Acta Neurol Scand 67 (1983) $131-142$.

12. Overton DA. State-dependent learning produced by depressant and atropine-like drugs. Psychopharmacology 10 (1966) 6-31. 
13. Overton DA. Differential responding in a three choice maze controlled by three drug states. Psychopharmacology 11 (1967) 367-378.

14. Sandemose A. En flygtning krydser sit spor: II Espen Arnakkes kommentarer til Janteloven. Vinten, Copenhagen 1963.

Anders Gade, $\mathrm{PhD},{ }^{1}$ Hans Henrik Jensen, $\mathrm{PhD}^{2}$

${ }^{1}$ Section of Neuropsychology, Department of Neurology N 2081, Rigshospitalet, Blegdamsvej 9, DK-2100 Copenhagen, Denmark.

2 Psychological Laboratory, Copenhagen University, Njalsgade 94, DK-2300 Copenhagen, Denmark. 